\title{
TONGKAT BANTU JALAN TUNANETRA PENDEKTESI HALANGAN MENGGUNAKAN SENSOR ULTRASONIK BERBASIS MIKROKONTROLER ARDUINO NANO
}

\author{
Muhammad Rio, Zunita Wulansari \\ Program Studi Sistem Komputer S1, Fakultas Teknik Informatika \\ Universitas Islam Balitar, Jalan Majapahit Blitar, Indonesia \\ Mrio10404@gmail.com
}

\begin{abstract}
ABSTRAK
Tunanetra adalah penyakit yang diderita oleh manusia. Hilangnya fungsi indra penglihatan maka sering kita lihat banyak penyandang tunetra yang mengalami kecelakaan dalam menjalani kegiatan sehari-hari. Oleh karena itu peneliti mengambil judul tongkat bantu jalan tunanetra pendeteksi halangan menggunakan sensor ultrasonik berbasis mikrokontroler arduino nano. Media yang digunakan dalam pembuatan tongkat alat bantu jalan bagi tunanetra berupa tongkat dengan perangkat keras arduino nano, menggunakan sensor ultrasonik HCSR04 yang dapat membaca jarak yang telah diprogram di Arduino Nano dan sebuah output berupa buzzer 5 V. Jangkauan yang dapat dideteksi tongkat bantu jalan ini adalah halangan yang berada dalam jarak $5 \mathrm{~cm}$ sampai $50 \mathrm{~cm}$ halangan didepan pengguna. Apabaila jarak halangan dengan sensor lebih dari $50 \mathrm{~cm}$ maka buzzer tidak akan berbunyi atau tidak ada halangan. Dan hasil pengujian daya tahan baterai untuk alat bantu jalan tunanetra diperoleh daya tahan baterai dengan daya maksimum 3,6 Wh dalam maksimal 9 jam kondisi baterai digunakan secara terus menerus atau dalam kondisi buzzer menyala selama 9 jam.
\end{abstract}

\section{Kata kunci : Tunanetra, Arduino Nano, Tongkat}

\section{PENDAHULUAN}

\subsection{Latar Belakang}

Hilangnya fungsi indra penglihatan maka sering kita lihat banyak penyandang tunetra yang mengalami kecelakaan dalam menjalani kegiatan sehari-hari. Defini Tunanetra menurut Yusuf (1996: 21) menjelaskan bahwa pengertian buta atau tunanetra, meskipun dengan alat bantu menggambarkan keadaan dimana penglihatan tidak bisa objektif lagi yang berakibat mengandalkan terhadap fungsi panca indra lainnya.

Bahkan tidak hanya untuk perangkat elektronik saja, penggunaan teknologi mikrokontroler hari-hari ini makin berkembang pesat. Sensor merupakan salah satu teknologi yang bekerja di mikrokontroler. Sensor adalah perangkat yang dapat digunakan untuk mendeteksi fenomena lingkungan juga perubahan besaran fisik seperti cahaya, kecepatan, besaran listrik, gaya, tekanan, kelembaban, gerakan, suhu, dan lain-lain.

Pada dasarnya sensor ultrasonik sangat bermanfaat dan bisa diterapkan sebagai alat untuk membantu jalan bagi penyandang tunanetra, alat ini mampu mendeteksi benda atau halangan yang dapat memantulkan gelombang sensor ultrasonik sebagai input kemudian hasilnya atau outputnya berupa bunyi buzzer yang bisa didengarkan oleh penyandang tunanetra, sehingga para penyandang tunanetra dapat merasa meringankan kewaspadaan setiap akan aktivitas berjalan atau bergerak. Oleh karena itu tujuan menggunakan sensor ultrasonik pada penelitian ini yaitu sensor bisa mendeteksi suatu halangan atau benda yang kita bisa mengatur berapa jauh jarak pengguna kehalangan tersebut dan sensor juga dilengkapi dengan buzzer yang akan berbunyi jika sensor mendeteksi halangan atau benda.

\subsection{Rumusan Masalah}

Di lihat dari latar belakang diatas maka peneliti mengambil rumusan masalah yaitu :

1. Bagaimana membuat tongkat bantu jalan tunanetra pendeteksi halangan menggunakan sensor ultrasonik berbasis mikrokontroler arduino nano ?

2. Bagaimana hasil pengujian tongkat bantu jalan tunanetra pendeteksi halangan menggunakan sensor ultrasonik berbasis mikrokontroler arduino nano ?

\section{TINJAUAN PUSTAKA}

\subsection{Penelitian Terdahulu}

Andi Irawan (2018) melakukan penelitian yang berjudul sepatu alat tunanetra menggunakan sensor ultrasonik HC-SR04 dan sensor warna TCS3200 berbasis arduino nano atmega328. Penelitian tersebut mengembangkan sebuah prototype beserta software aplikasi untuk membantu kesulitan bagi penyandang tunanetra, dimana peneliti membuat sebuah alat yang mampu mendeteksi dan sekaligus sebagai pembaca warna TCS3200. Berikut ini merupakan hasil dari penelitian tersebut. Pertama, sebagai pengukur jarak terhadap halangan, sepatu ini menggunakan sensor ultrasonik HC-SR04 dan sebagai pembaca warna menggunakan sensor TCS3200. Kedua, sebagai penanda jarak serta warna menggunakan buzzer dan penggetar. Sensor HC-SR04 digunakan mendeteksi 
penghalang dengan jarak tertentu yang kemudian mengaktifkan buzzer, jika objek semakin dekat maka frekuensi buzzer akan bertambah besar. Ketiga TCS3200 mempunyai fungsi membaca warna kuning, biru, merah.

\subsection{Landasan Teori}

\subsubsection{Tunanetra}

Yusuf (1996: 21) menjelaskan bahwa pengertian buta atau tunanetra, meskipun dengan alat bantu menggambarkan keadaan dimana penglihatan tidak bisa objektif lagi yang berakibat mengandalkan terhadap fungsi panca indra lainnya.

\subsubsection{Sensor Ultrasonik}

Alat ukur jarak berbasis gelombang ultrasonik menggunakan sensor HC-SR04. Radar ultrasonik mempunyai prinsip kerja setara dengan sensor HCSR04. Gelombang ultrasonik yang dipancarkan diterima kembali oleh receiver ultrasonik. Jangkauan antara timming pancaran dan timming receiver merupakan penggambaran terhadap jangkauan pada objek. Sensor ini cocok diaplikasikan pada elektronik yang membutuhkan deteksi jangkauan sensor pada robot.

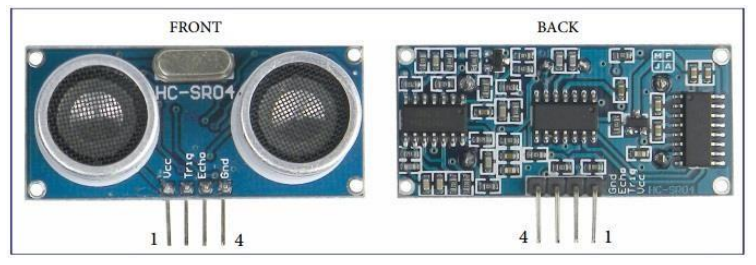

Gambar 1 Sensor HC-SR04

\subsubsection{Mikrokontroler}

Mikrokontroler merupakan IC yang mempunyai kepadatan sangat tinggi Menurut Setiawan (2011:1), biasanya terdiri dari RAM (Random Access Memory), CPU (Central Processing Unit), I/O, Timer, Serial \& Parallel, EEPROM/EPROM/PROM/ROM yang semua bagiannya memerlukan suatu kontroler yang telah dirakit kedalam sebuah kepingan.

\subsubsection{Arduino Nano}

Merupakan suatu board mikrokontroler yang mempunyai ukuran mikro dengan kelengkapan yang mampu mensupport pada saat menggunakan breadboard. Dengan basis microcontroller Atmega 16 (Arduino versi 2.x) atau ATmega328 (Arduino nano versi 3.x) Arduino Nano tersebut diciptakan. Arduino nano memiliki fungsi yang kurang lebih hampir signifikan dengan Arduino Duemilanove akan tetapi berbeda dalam paketnya.

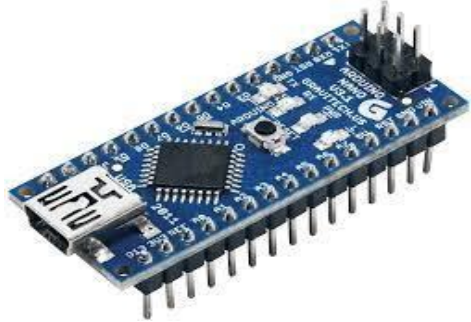

Gambar 2 Arduino Nano

\section{METODE PENELITIAN}

\subsection{Langkah-langkah Model Pengembangan} ADDIE

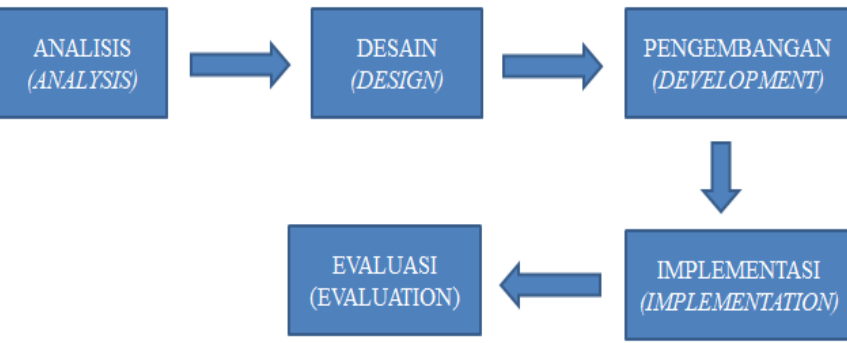

Gambar 3 Langkah-langkah Model Pengembangan ADDIE

Penjelasan dari gambar tersebut yaitu :

1. Pada tahap analisis diawali dengan menganalisis perlunya pengembangan untuk media alat penunjuk arah bagi tunanetra dan menganalisis kelayakan syarat-syarat untuk media pengembangan alat.

2. Setelah itu melakukan tahap desain penetapan dan perencanaan serta perancanganproduk berdasarkan informasi yang didapat dari tahapan sebelumnya.

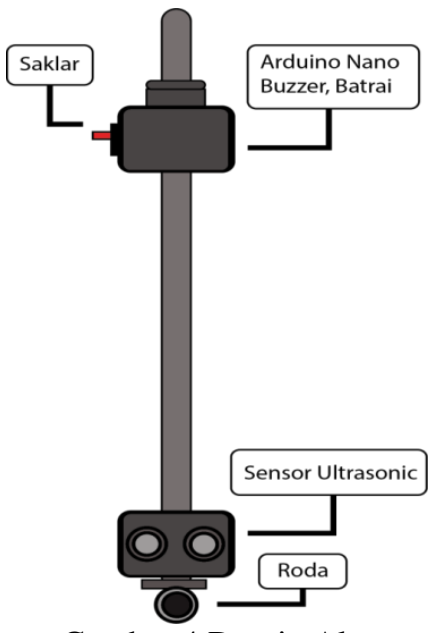

Gambar 4 Desain Alat 
(a) Mikrokontroler atau Arduino Nano

Seluruh komponen yang terhubung ke Arduino Nano pada mikrokontroler ini menggunakan Arduino Nano sebagai fungsi pengendalinya. Pengendalian tersebut bertujuan agar supaya bisa berjalan sesuai program terhadap modul-modul yang telah terhubung ke Arduino Nano.

(b) Sensor ultrasonik HC-SR04

Di tahap ini ultrasonik sensor HC-SR04 sebagai fungsi deteksi halangan dengan keberadaan objek didepan atau dikanan kiri pengguna.

(c) Buzzer

Dari sensor ultrasonik HC-SR04 Buzzer digunakan sebagai media output, serta output dari sensor ultrasonik berupa suara. Suara akan terjadi apabila sensor mendeteksi kalau ada halangan didepan pengguna.

(d) Breadboard mini atau printed circuit board (pcb)

Breadboard mini disini berfungsi sebagai merancang sebuah rangkaian elektronik sederhana dan sebagai wadah untuk meletakkan setiap komponen.

(e) Black Box atau Kotak Hitam

Black Box atau Kotak Hitam sebagai media untuk wadah seluruh komponen-komponen yang menunjang alat tersebut.

Untuk mengetahui acuan dasar dalam membuat rangkaian merupakan tujuan dari perancangan hardware (perangkat keras). Setiap alat mempunyai fungsi tertentu dan berdasarkan rancangan diagram blok dapat dilakukan desain rancangan, setelah rangkaian dibuat dapat dilakukan pemilihan komponen.

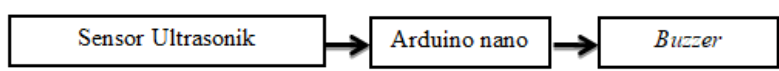

Gambar 5 Diagram Blok

Prinsip kinerja diagram blok diatas adalah sensor ultrasonik sebagai input mendeteksi suatu benda yang dideteksi, lalu diproses dalam arduino nano apabila jarak benda dengan sensor dibawah 50 $\mathrm{cm}$ maka program akan diteruskan ke-buzzer dan akan berbunyi, apaila jarak sensor dengan benda yang dideteksi lebih dari $50 \mathrm{~cm}$ maka proses tidak akan dilanjutkan .

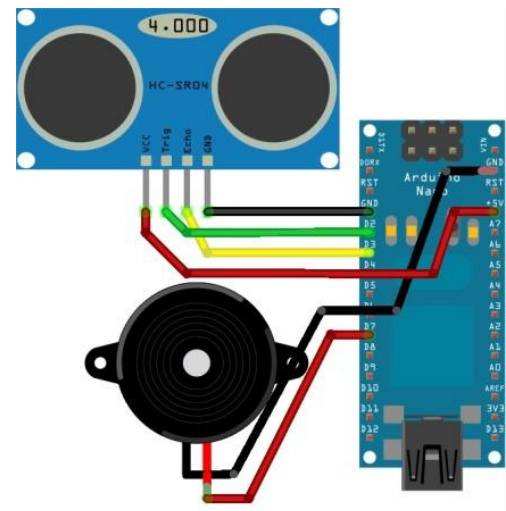

Gambar 6 Rangkaian Alat

Tabel 1 Konfigurasi Pin

\begin{tabular}{|c|c|}
\hline Pin & Komponen \\
\hline Vcc & kaki 5 V arduino nano \\
\hline GND & Kaki GND \\
\hline D3 & Kaki echo sensor ultrasonik \\
\hline D2 & Kaki trigger sensor ultrasonik \\
\hline D7 & Kaki positif buzzer \\
\hline
\end{tabular}

Alur Flowchat atau Perangkat Lunak :

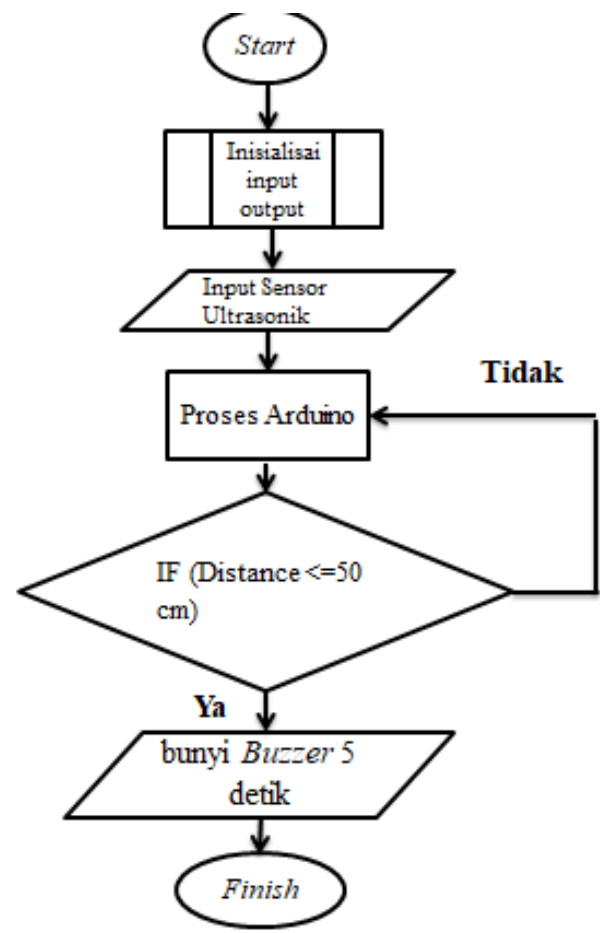

Gambar 7 Flowchart sistem tongkat tunanetra untuk bantu jalan 
Penjelasan terhadap skema gambar 7 flowchat sistem bagi tunanetra untuk alat bantu jalan :

(a) Tahap awal, dari inisialisasi input output untuk memastikan perangkat sudah terhubung dengan mikrokontroler.

(b) Tahap kedua, sensor ultrasonik mendeteksi adanya halangan.

(c) Tahap ketiga, melakukan proses yang dilakukan diarduino nano.

(d) Tahap keempat, jika sensor mendeteksi $<=50$ cm maka akan diteruskan ketahap 5 .

(e) Tahap kelima, jika sensor mendeteksi $>50 \mathrm{~cm}$ maka akan kembali ketahap 2 yaitu dilakukan proses.

(f) Tahap keenam setelah sensor mendeteksi halangan $<=50 \mathrm{~cm}$ buzzer akan berbunyi selama 5 detik.

(g) Tahap ketuju, selesai.

3. Selanjutnya kita berlanjut pada tahap pengembangan (development) yaitu tahap agar menjadi sebuah produk diperlukan realisasi terhadap desain yang telah dibuat.

4. Setelah itu ke tahap implementasi dalam menerapkan rancangan alat bantu bagi tunanetra sebagai pendeteksi terhadap penghalang yang memakai basis mikrokontroler arduino nano sebagai sensor ultrasonik yang dibuat dalam situasi nyata guna melihat sistem maupun instruktur yang telah siap di uji coba dan ditahap implementasi pula maka kita bisa melihat alat sudah dapat berjalan sesuai program atau proses yang kita jalan atau belum.

5. Dan tahap terakhir yaitu tahap evaluasi proses untuk menganalisa prototype atau program pada penerapannya masih memiliki hal yang kurang ataupun tidak. Jika implementasinya tidak terdapat revisi lagi maka rancangan alat bantu jalan bagi tunanetra sebagai deteksi penghalang yang memakai basis mikrokontroler arduino nano sebagai sensor ultrasonik maka layak digunakan.

\subsection{Teknik Pengumpulan Data}

(a) Wawancara adalah pengumpulan data yang dilakukan dengan tanya jawab secara langsung atau tatap muka antara narasumber setelah membuat alat.

(b) Observasi merupakan teknik pengumpulan data dengan cara terjun langsung ke tempat kejadian perkara guna mengamati problem yang terjadi dengan terstruktur mengenai kejadian, perilaku, objek yang terlihat serta hal lain yang memang diperlukan sebagai pendukung penelitian.

(c) Studi literatur merupakan teknik pengumpulan data dengan mengumpulkan referensi paper, jurnal, serta bahan bacaan lainnya yang memang memiliki hubungan terhadap penelitian.

\section{HASIL DAN PEMBAHASAN}

\subsection{Hasil Pengujian Alat}

Subjek penelitian ini adalah seorang penyandang tunanetra tidak memungkinkan peneliti mengambil sebelas sempel dalam pengujian alat ini, namun hanya menggunakan 2 indikator sensor mendeteksi dan tidak mendeteksi, atau buzzer menyala dan tidak menyala. Demi membuktikan tongkat ini berjalan dengan baik, peneliti menampilkan data sebagai berikut, mulai dari jarak 5 cm sampai $50 \mathrm{~cm}$ buzzer akan berbunyi dan berfungsi dengan baik, setelah sensor ultrasonik mendeteksi halangan selama 5 detik. Apabila jarak $55 \mathrm{~cm}$ sampai $100 \mathrm{~cm}$ maka buzzer tidak akan berbunyi sesuai dengan jarak sensor ultrasonik yang menuju halangan.

Agar lebih meyakinkan data jarak sensor dengan halangan sama, peneliti menampilkan sebuah data yang ditampilkan dalam serial monitor Arduino IDE. Kondisi baterai juga berpengaruh pada pendeteksian jarak, apabila kondisi baterai 60 - 100\% maka dapat medeteksi $5 \mathrm{~cm}-50 \mathrm{~cm}$. apabila kondisi baterai kurang dari normal maka pendeteksian jarak tidak akan berjalan dengan baik. Dari hasil survey lima orang penyandang tunanetra berputar dan membalikan badan diperoleh diameter putarannya 1,5 meter dari badan sensor ultrasonik. Jadi jarak $50 \mathrm{~cm}$ adalah jarak perputaran ujung tongkat dan benda yang disensor agar tidak terjadi benturan.

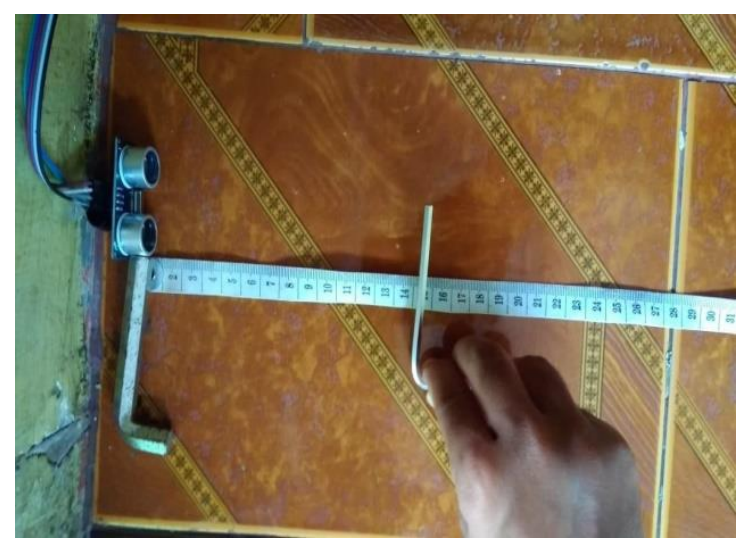

Gambar 7 Percobaan ke-1

Gambar diatas menunjukkan pengukuran sensor HCSR04 pada jarak $15 \mathrm{~cm}$.

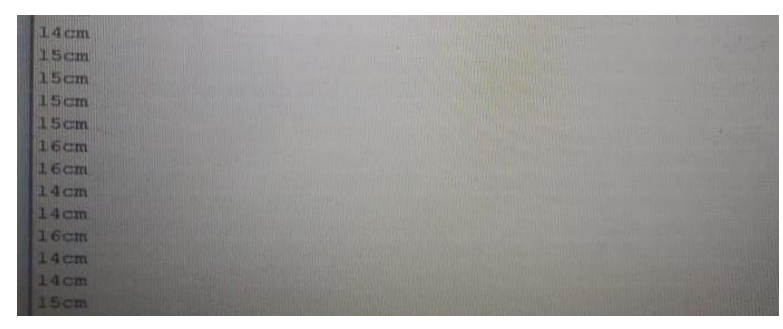

Gambar 8 Hasil Serial Monitor ke-1 
Gambar diatas menunjukkan hasil pengukuran sensor HC-SR04 dengan jarak $15 \mathrm{~cm}$ pada serial monitor maka output buzzer akan berbunyi setelah sensor ultrasonik mendeteksi halangan selama 5 detik.

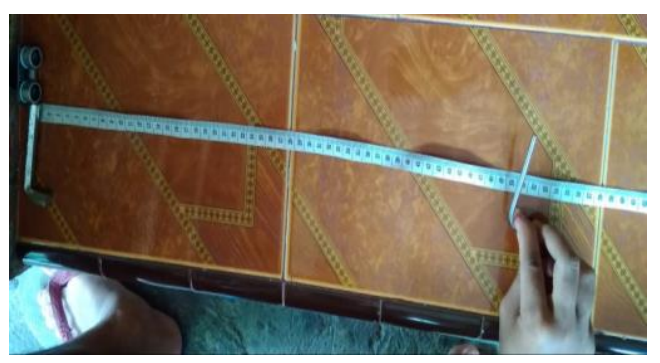

Gambar 9 Percobaan ke-2

Gambar diatas menunjukkan pengukuran sensor HC-SR04 pada jarak $50 \mathrm{~cm}$.

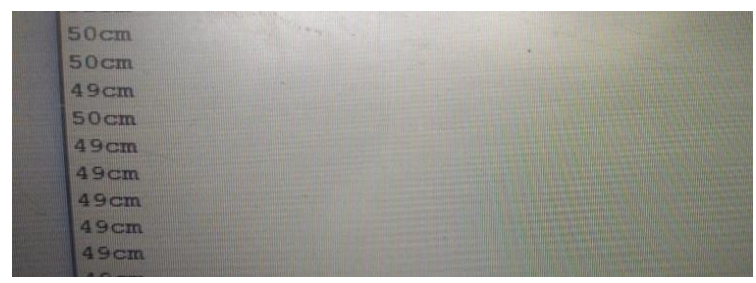

Gambar 10 Hasil Serial Monitor ke-2

Gambar diatas menunjukkan hasil pengukuran sensor HC-SR04 dengan jarak $49 \mathrm{~cm}$ pada serial monitor maka output buzzer akan berbunyi setelah sensor ultrasonik mendeteksi halangan selama 5 detik.

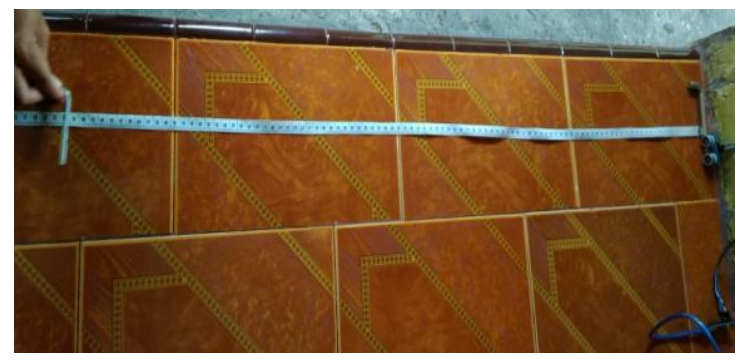

Gambar 11 Percobaan ke-3

Gambar diatas menunjukkan pengukuran sensor HC-SR04 pada jarak $100 \mathrm{~cm}$.

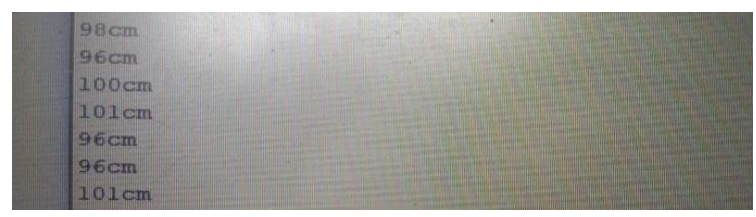

Gambar 12 Hasil Serial Monitor ke-3
Gambar diatas menunjukkan hasil dari pengukuran sensor HC-SR04 yang memiliki jarak $100 \mathrm{~cm}$ di serial monitor, maka output buzzer akan berbunyi setelah sensor ultrasonik mendeteksi halangan selama 5 detik.

Tabel 2 Hasil Pengujian Alat

\begin{tabular}{|c|c|c|c|c|}
\hline & Jarak & Jarak & \multicolumn{2}{|c|}{ Output Buzzer } \\
\cline { 4 - 5 } & $\begin{array}{c}\text { Sensor } \\
\text { Sebenarnya } \\
(\mathrm{cm})\end{array}$ & $\begin{array}{c}\text { Merial } \\
\text { Monitor } \\
(\mathrm{cm})\end{array}$ & Bunyi & Tidak \\
\hline 1. & 5 & 5 & $\checkmark$ & \\
\hline 2. & 10 & $9-10$ & $\checkmark$ & \\
\hline 3. & 15 & 15 & $\checkmark$ & \\
\hline 4. & 20 & 19 & $\checkmark$ & \\
\hline 5. & 40 & 40 & $\checkmark$ & \\
\hline 6. & 50 & 49 & $\checkmark$ & \\
\hline 7. & 55 & 55 & & $\checkmark$ \\
\hline 8. & 60 & 59 & & $\checkmark$ \\
\hline 9. & 80 & $79-80$ & & $\checkmark$ \\
\hline 10. & 95 & 94 & & $\checkmark$ \\
\hline 11. & 100 & $99-100$ & & $\checkmark$ \\
\hline
\end{tabular}

Dari hasil analisis uji coba tabel 1 diatas maka kita bisa ketauhi bahwa sensor ultrasonik dapat mendeteksi halangan didepan dengan jarak $5-50 \mathrm{~cm}$ yang sudah diprogram terlebih dahulu ke arduino nano. Jika sensor ultrasonik dapat mendeteksi halangan dengan jarak 5- $50 \mathrm{~cm}$ maka buzzer akan mengeluarkan bunyi setelah sensor ultrasonik mendeteksi halangan selama 5 detik maka dari sana tongkat menemukan halangan. Apabila sensor mendeteksi halangan dengan jarak $55 \mathrm{~cm}$ sampai 100 $\mathrm{cm}$ maka buzzer tidak akan mengeluarkan bunyi sesuai dengan jarak yang sudah ditentukan oleh sensor ultrasonik yang dipgoram oleh arduino nano dan tongkat masih belum mendekeksi adanya halangan.

\subsection{Uji Coba Daya Tahan Baterai}

Tabel 3 Uji Coba Daya Tahan Baterai

\begin{tabular}{|c|c|c|c|}
\hline $\begin{array}{c}\text { Tegangan } \\
\text { Baterai ( V ) }\end{array}$ & $\begin{array}{c}\text { Arus } \\
\text { Baterai } \\
(\mathrm{Ah})\end{array}$ & $\begin{array}{c}\text { Daya } \\
\text { Baterai } \\
(\mathrm{Wh})\end{array}$ & $\begin{array}{c}\text { Waktu } \\
(\mathrm{Jam})\end{array}$ \\
\hline 9 & 0,4 & 3,6 & 9 jam \\
\hline 7,73 & 0,4 & 3,092 & 7 jam \\
\hline 4,5 & 0,4 & 1,8 & 4,5 jam \\
\hline 0 & 0,4 & 0 & 0 \\
\hline
\end{tabular}

Perhitungan daya tahan baterai dengan mengetauhi besar tegangan dan kapasitas yang dimiliki baterai. Betarai yang digunakan memiliki tegangan $9 \mathrm{v}$ dan kapasitas $400 \mathrm{mAh}$. Langkah pertama yaitu mengkonfersi kapasitas baterai 400 mAh menjadi 0,4 Ah, maka daya baterai diketauhi 0,4 Ah $\times 9 \mathrm{v}=3,6 \mathrm{Wh}$. Alat ini mengkonsumsi kurang lebih 0,4 Watt. Jadi daya tahan yang dimiliki baterai tersebut dapat dihitung dengan rumus daya 
baterai dibagi konsumsi daya alat. Maka 3,6 Wh : 0,4 Watt didapat waktu 9 jam.

\section{KESIMPULAN DAN SARAN}

\subsection{Kesimpulan}

1. Sistem kinerja pada tongkat alat bantu tunanetra ini dibangun dengan sebuah sistem Arduino IDE. Media yang digunakan dalam pembuatan tongkat alat bantu jalan bagi tunanetra berupa tongkat dengan perangkat keras arduino nano, menggunakan sensor ultrasonik HC-SR04 yang dapat membaca jarak pada jarak yang telah diprogram di Arduino Nano dan sebuah output berupa buzzer $5 \mathrm{~V}$.

2. Dari hasil pengujian alat dengan responden penyandang tunanetra didapatkan bahwa buzzer akan berbunyi apabila sensor mendeteksi sebuah halangan dalam jangkauan sensor ultrasonik dibawah $50 \mathrm{~cm}$. Apabaila jarak halangan dengan sensor lebih dari $50 \mathrm{~cm}$ maka buzzer tidak akan berbunyi atau tidak ada halangan. Dan dari hasil pengujian daya tahan baterai diperoleh daya tahan baterai dengan daya maksimum 3,6 Wh dapat digunakan maksimal 9 jam kondisi, baterai digunakan secara terus menerus atau dalam kondisi buzzer menyala selama 9 jam.

\subsection{Saran}

1. Peneliti berharap penelitian ini bisa dikembangkan kedepannya seperti dengan ditambahnya sensor untuk deteksi keberadaan selokan atau lubang.

2. Tongkat ini diharapkan memiliki bentuk yang lebih fleksibel agar dapat digunakan secara nyaman oleh pengguna.

3. Tongkat ini masih perlu banyak dikembangkan, perlu penelitian lebih lanjut agar Tongkat ini dapat diaplikasikan secara efektif dan efisien pada penyandang tunanetra.

\section{DAFTAR PUSTAKA}

[1] Andi Irawan. 2018. Sepatu alat tunanetra menggunakan sensor ultrasonik HC-SR04 dan sensor warna TCS3200 berbasis arduino nano atmega328. Fakultas teknik. Universitas Lampung.

Junfithrana dan Ade Anggy Pradiftha
Rancang Bangun Alat Bantu Jalan Untuk Penyandang tunanetra Berbasis Ardui Jurnal Rekayasa Nusaputra Vol 1 No. 1.

[3] Edi Purnomo. 2013. Rancang Bangun Alat Bantu Penunjuk Arah Jalan Untuk Penyandang Tunanetra Menggunakan Teknologi Sensor Warna dan Sensor Ping. Skripsi. Teknik Elektro dan Fakultas Sains. Universitas Islam Negeri Sultan Syarif Kasim : Riau Pekanbaru.

[4] Mahmoud, Ayat A. Nada, Ahmed F. 2015. Assistive Infrared Sensor Based Smart Stick For Blind People. Journal. University Helwan : Egypt.

[5] Miguel Reyes. 2015. Navigating Blind People With a Smart Walker. Journal. Hamburg : Germany.

[6] Muhammad, Ilham dkk (2015) Aplikasi Alat Bantu Baca Buku untuk Tunanetra menggunakan Portable Scanner dengan Metode Hard-Text to Voice Prodi D3 Teknik Informatika, Fakultas Ilmu Terapan, Universitas Telkom.

[7] Syam, Rafiuddin. 2013. Dasar Dasar Teknik Sensor. Fakultas Teknik Universitas Hasanuddin. Makassar. 